\title{
Escritoras de la posguerra frente al espejo. Derrotas y conquistas de algunas antiheroínas
}

\author{
Natalia Izquierdo López \\ Profesora de lengua castellana y literatura de ESO. Región de Murcia \\ notesalvesahora@hotmail.com
}

\section{Resumen}

El presente ensayo toma como punto de partida para su análisis el material autobiográfico de dos escritoras de la posguerra: Carmen Laforet y Carmen Martín Gaite. Siguiendo el método de la genealogía histórica, la investigación aborda el peso ejercido en sus vidas por los procesos de socialización, las formas y las estrategias de las que dichas autoras se sirvieron para romper, en la medida en que pudieron, con el dispositivo de feminización — entendido como programa de domesticación de la mujer-. Además, muestra las distintas imágenes que elaboraron de sí mismas en tanto plasmaciones de su lucha, más o menos fructífera, en aras de una mayor independencia y autonomía.

Palabras clave: Carmen Laforet; Carmen Martín Gaite; autobiografías; socialización; autopercepción; independencia.

Abstract. Post-war writers facing the mirror: Defeats and achievements of some anti-heroines

This article takes as a starting point the autobiographical material of two writers of the post-war era: Carmen Laforet and Carmen Martín Gaite. Following the method of historical genealogy, this research deals with the weight exerted on their lives by the socialization processes, forms and strategies that these authors made use of, where they could, to break with the device of feminization - understood as a program of women's domestication. The article also explores the different images that they developed of themselves as embodiments of their more or less successful struggle to gain greater independence and autonomy.

Keywords: Carmen Laforet; Carmen Martín Gaite; autobiographies; socialization; selfperception; independence.

\section{Sumario}

Introducción

1. El feminismo «sui generis» de Carmen Laforet
2. El mundo propio y el feminismo "a su manera» de Carmen Martín Gaite

3. Conclusión

Referencias bibliográficas 


\section{Introducción}

Este trabajo se basa en los textos autobiográficos de Carmen Laforet y de Carmen Martín Gaite, dos escritoras cuya adolescencia transcurrió en la posguerra inmediata, periodo histórico que entrañó un claro freno al proceso de emancipación puesto en marcha por las mujeres españolas en las primeras décadas del siglo XX. En dicho contexto, el nacionalcatolicismo y los distintos agentes de la moral instituida - Iglesia, poder político, Sección Femenina, etc. - implantaron un programa de domesticación de la mujer destinado a convertirla en madre ejemplar, amante esposa y sacrificada ama de casa. Dicho programa estaba en consonancia con la noción de dispositivo de feminización descrita por la catedrática de Sociología Julia Varela en su libro El nacimiento de la mujer burguesa. Con dicho concepto, la investigadora ha aludido a un sistema de racionalización de la vida de las mujeres que, desde tiempo atrás, nos ha negado la condición de sujetos de la historia y de conocimiento y nos ha recluido en el espacio doméstico, desde donde, a su vez, nos ha impedido el acceso al mundo social y al ejercicio del poder político en tanto nos ha atribuido otro ligado al gobierno de la casa y la crianza de los hijos, así como a la gestión de la esfera de la intimidad, sobre la que nuestra subjetividad femenina debía supuestamente girar (Varela, 1997). Este dispositivo de feminización ha sido, a su vez, uno de los elementos de los que el discurso de la razón patriarcal se ha servido históricamente para construir y afianzar la supuesta diferencia femenina, vinculándola, precisamente, a los valores de la vida, la inmanencia, la maternidad, la emocionalidad y la naturaleza por oposición a la cultura, la universalidad y la trascendencia que definirían a la masculinidad. En este contexto, numerosos estudios de género se han planteado la necesidad de impugnar la conceptualización masculina de nuestra diferencia y la de reconciliarnos con nuestra propia diferencialidad, dado que, como tales investigaciones sostienen, «ninguna lucha es posible ni nada podría ser construido desde la propia desvalorización, [...] producto de [...] la asunción como propia de la inferioridad que nos atribuye el otro» (Amorós, 1991: 137). Además, desde tales estudios de género, se ha defendido asimismo el postulado de que la autonomía y el cambio de la situación real de las mujeres pasa por dotarlas y que se doten de una «nueva conciencia de sí no inferiorizada", es decir, por la creación de "ciertos mecanismos de autoafirmación» (Amorós, 1991: 152). Teniendo en cuenta estas consideraciones como punto de partida, nuestro estudio lleva a cabo el análisis sociohistórico de las trayectorias vitales de Carmen Laforet y de Carmen Martín Gaite, poniendo el énfasis en la conciencia de sí de la que ambas artistas se dotaron a partir de los modelos y las conceptualizaciones de otras mujeres, de la influencia de y como reacción a sus medios sociales. No obstante, es posible que la elección de la conciencia de sí como categoría de análisis sea deslegitimada por quien piense más en términos de racionalidad científica o abstracta, así como por los adscritos y las adscritas a posiciones sociales dominantes que proporcionan, de suyo, seguridad y autoestima para batallar en la vida. Sin embargo, con la elección de esta categoría, nuestra investigación se inscribe de lleno en el marco de los 
estudios de género sobre la crítica de la razón patriarcal referidos más arriba, al mismo tiempo que asume como hipótesis guía para su trabajo los postulados antes mencionados, a su vez recogidos por Celia Amorós en su homónima y ya célebre colección de ensayos (Amorós, 1991). Desde este punto de vista, nuestro estudio muestra la evolución de Carmen Laforet y de Carmen Martín Gaite desde el temprano menosprecio de sí, producto de la interiorización de la opresión del otro —entendiendo por "otro" tanto a los varones como a las féminas que habían aceptado la definición patriarcal acerca de su diferencia-, hasta el surgimiento en ambas mujeres de una conciencia emergente y dotada de un eminente potencial crítico, no sólo contra el programa de domesticación y el dispositivo de feminización ya aludidos, sino en relación con la manera en que la dominación masculina había construido la supuesta especificidad de lo femenino. Asimismo, nuestro estudio apunta cómo las dos artistas se reconciliaron con su propia diferencialidad y se dotaron de mecanismos de autoafirmación más o menos efectivos, manteniendo, precisamente, unas relaciones de aproximación distancia con distintos feminismos, más en particular el de la diferencia y el de la igualdad. En este sentido, Carmen Laforet abogó por un feminismo que hemos apelado «sui generis», en tanto que Carmen Martín Gaite dijo tener uno «a su manera». Diríase, pues, que, frente a los feminismos mencionados más arriba, ambas escritoras adoptaron una posición de «marginación integrada» o de «integración marginal». Ha sido precisamente esta posición la que nos ha llevado a calificarlas de «antiheroínas», ya que la misma parece ligada a su deseo de captar su propia especificidad, no sólo dejando atrás la desvalorización patriarcal, sino también los planteamientos más radicales del feminismo de la diferencia y del de la igualdad, así como la conciencia exaltada de sí de la que hacen gala a veces las mujeres que los defienden (Amorós, 1991: 73).

\section{El feminismo «sui generis» de Carmen Laforet}

Así soy yo, una batalla y una tormenta, un puñado de sentimientos siempre en lucha. [...]

Sé que nací para vagabunda. (Carmen LAforet. Música blanca)

\subsection{La niña que no se gustaba a si misma}

Carmen Laforet nació en Barcelona el 6 de septiembre de 1921. Enseguida, sus padres se mudaron a Las Palmas y, poco después, a un paraje cercano en la montaña. En plena mudanza, Carmen sufrió un accidente doméstico que le ocasionó una grave herida en el esófago, a raíz de la cual no pudo ingerir alimentos sólidos con normalidad hasta los ocho años, por lo que se percibió a sí misma como una "niña bastante feúcha y como raquítica» (Cerezales, 2009: 242). Una vez pudo seguir un régimen alimenticio normal, comenzó a engordar y a «aborrecer su cara» (Cerezales, 2009: 239). Su padre, Eduardo 
Laforet, arquitecto del Cabildo Municipal de Las Palmas, había destacado en varias disciplinas deportivas y, puesto que "tener una hija gorda le desesperaba», sometió a la niña a un severo régimen que, por su desobediencia, no sirvió de nada (Cerezales, 2009: 239). El rechazo de su progenitor suscitó que Carmen no se sintiera jamás a gusto con su fisonomía, así como su preferencia por la extrema delgadez que siempre la caracterizaría, no dudando incluso a preservarla automedicándose durante un tiempo a base de anfetaminas.

A los cuatro años, la escritora comenzó a asistir a un parvulario regentado por monjas, del que dijo ser "un mundo mágico que le pertenecía» (Cerezales, 2009). Su infancia transcurrió entre cómplices y atrevidos juegos con sus dos hermanos — ambos menores que ella—, los niños y niñas de las casas de campo y las villas vecinas y los hijos e hijas de los pescadores de San Cristóbal, un poblado cercano. Todo esto fomentó en ella relaciones de igual a igual con el otro género, vínculos interclasistas y un fuerte deseo de autonomía. Mientras que su padre detentaba en la casa el poder jerárquico y la supremacía, su madre, Teodora Díaz, «una mujer menuda, de enorme energía espiritual, de agudísima inteligencia y un sentido castellano, inflexible, del deber», que había cursado la Primera Enseñanza en la sección gratuita para niñas pobres y obtenido una beca para estudiar la carrera de maestra, se consagraba a fomentar en sus hijos el afán de lectura y el desarrollo intelectual (Laforet, 1957). Además, se mostraba mucho más proclive que su marido a favorecer las inclinaciones de los mismos, a quienes Eduardo Laforet forzaba a que compartieran sus aficiones.

\subsection{Una adolescencia vagabunda y huérfana}

En 1934, Teodora Díaz falleció a causa de un proceso infeccioso. A raíz de este luctuoso hecho, la adolescente se declaró a sí misma mayor de edad, lo que puede interpretarse como un claro desafío a la autoridad del padre, que enseguida contrajo matrimonio con Blasa la Chica, una mujer de extracción popular que sentía celos de la niña. Por parte de ésta, comenzaron primero a sucederse gritos, rabietas y rotura de vajillas durante las comidas. Después, vendrían los encierros y las palizas, la prohibición de viajar con su padre a solas en el coche hasta Las Palmas — donde Carmen cursaba ya su enseñanza secundaria-, el distanciamiento forzoso de sus hermanos, convertidos por su madrastra en "carceleros de la jovencita», así como la destructora furia con que comenzó a romper las fotografías, los vídeos y las dedicatorias de Teodora Díaz. La reacción de su padre ante los desvaríos de Blasa no iba más allá de sentarse en un rincón confortable, encender su pipa y ponerse a leer hasta que se marchaba a Las Palmas. Durante este período, Carmen sintió una fuerte necesidad de afecto que intentó combatir vagabundeando, solitaria, por montes y playas cercanas. Fue entonces cuando arraigó en ella la pasión por el nomadismo y la bohemia, así como la contradicción entre, por un lado, sus carencias afectivas y, por otro, su acendrado orgullo y su deseo de autonomía (Cerezales, 2009: 174). Por la misma época, conoció también a Ricardo Lezcano, un joven canario que estaba estudiando profesorado mercantil en Barcelona cuando 
estalló la guerra, en la que había combatido en el bando republicano. Cuatro años mayor que ella, Ricardo ya había conocido una vida sexual intensa. Sus relaciones con él, presentadas por la escritora desde su imaginario romántico de aquellos años como de una «sensualidad inocente», llevaron a su madrastra a planear su ingreso en un correccional y a acusarla de vida disoluta y descarriada (Cerezales, 2009: 127). Temiendo esta circunstancia, así como que se le prohibiera continuar sus estudios en la Península, en septiembre de 1939, Carmen siguió a Ricardo en su viaje de vuelta a la misma. Para ello, hubo de chantajear a su padre, a quien amenazó con mostrar a toda la familia un fajo de cartas amorosas que había encontrado, escritas por éste a Blasa la Chica aún en vida de Teodora Díaz. A este respecto, contó además con el apoyo de su nueva profesora de lengua y literatura, Consuello Burell, formada en la Institución Libre de Enseñanza y refugiada política por sus ideas republicanas, así como de otras amigas canarias —-Lola de la Fe, Rosa Cajal, etc.- - Así, las restricciones, las prohibiciones y las injusticias que marcaron su adolescencia «significaron vientos favorables que empujaron las velas del barco de su independencia» (Cerezales, 2009: 231). También de este contexto de privación, rigor y violencia data su descubrimiento de la fantasía y la imaginación como formas de resistencia, y de la literatura como el «lugar en que ella podía expresar su malestar interior a los demás con cierta transparencia y libertad» (Caballé y Rolón, 2010: 345).

\subsection{Barcelona: ciudad de "nada" y de muchas expectativas}

A su llegada a Barcelona, Carmen se instaló en la casa de su abuela paterna, en el número 32 de la calle Aribau. El entorno empobrecido, desquiciado y de mentalidad reaccionaria de aquella casa hizo que pronto se truncaran sus relaciones con Ricardo Lezcano. Carente de nuevo de apoyo y afecto, se lanzó otra vez a vagar, solitaria, por la ciudad, hasta que, en 1940, se incorporó a la universidad. En el curso 1940-1941, se matriculó en siete asignaturas de Letras, a cuyos exámenes nunca se llegó a presentar. Tampoco hay constancia de que durante el siguiente continuara oficialmente en la universidad, aunque sí de que visitara el bar y el patio de la Facultad de Letras, donde los estudiantes improvisaban tertulias literarias. Fue en éstas donde conoció a sus dos mejores amigas de la época: Concha Ferrer y Linka Babecka. Por entonces, ambas eran estudiantes de Derecho y se dedicaban a buscar alojamiento a emigrantes polacos y anarquistas catalanistas exiliados en casas de la clase obrera, empresa en que Carmen les ayudaba. El entorno de las clases universitarias no le agradaba, porque, según algunos de sus compañeros, allí todos se reían de ella y la encontraban fuera de lugar por su desaliño al vestir, que ponía en evidencia la precaria condición de su hogar, así como el hecho de que ella cifraba la belleza, más que en el aspecto físico, en la inteligencia y la generosidad. Otros de los motivos que suscitaban el rechazo de sus compañeros eran, según éstos, su inclinación a la bohemia y sus «ideas pueriles, de un entusiasmo provinciano, atizado por lecturas tan entusiastas como desordenadas» (Caballé y Rolón, 2010: 123). En 
cambio, la joven se sentía a sus anchas viviendo «la inconsciencia absoluta y la descuidada felicidad» de la tertulia que varios artistas irreverentes y bohemios, también compañeros suyos de la Universidad, habían instalado en la planta baja del Palacio de la Virreina. Allí se congregaban, entre otros, Ramón Eugenio de Goicoechea, Ramón Rogert, Javier Vilató Ruíz y Mauricio Monsuárez de Yos.

A finales de 1942, sus dos amigas se ausentaron de Barcelona. La desorientación, el desamparo y el "punto muerto" en el que entró su vida al marcharse éstas, decidieron a Carmen Laforet a mudarse, siguiendo a Linka, a la capital madrileña.

\subsection{Madrid y el «envenenado reconocimiento» del Premio Nadal}

En la capital, Carmen se instaló en la casa de su tía materna, Carmen Díaz Molina, madre soltera de dos hijos a los que había educado sin complejos de ilegitimidad a pesar de la época. Ésta pronto comprendió «su triste orfandad» y, pese a la estrechez económica del hogar, «le destinó de inmediato un dormitorio independiente [...], con una pequeña mesa para escribir», siendo así la primera vez que Carmen dispondría de tal autonomía. (Caballé y Rolón, 2010: 140). Aunque inicialmente quiso estudiar Derecho — carrera de la que aprobó algunas asignaturas en los primeros cursos-, Laforet pasó la mayor parte del tiempo leyendo y escribiendo en el Ateneo madrileño. Por entonces, «[...] no aspiraba a sueldo, sino a viajar con el circo. [...] Pensaba también que, a lo mejor, pronto podría salir al extranjero y hacer labores de servicio doméstico» (Castilla del Pino, 1997: 287).

Sin embargo, en 1944, tras sugerirle ciertas modificaciones en el manuscrito de Nada, Manuel Cerezales, director de la editorial Pace, le instó a que lo presentara al Premio Nadal, que se acababa de convocar. En enero de 1945, la novela obtenía dicho galardón y se convirtió en un fulgurante éxito de ventas, saludado por escritores y críticos de la talla de Juan Ramón Jiménez, R. J. Sénder y José María de Cossío. La concesión del premio le trajo, por un lado, la ruptura de las relaciones con sus parientes barceloneses, a quienes había retratado ácidamente en su libro y, por otro, una vorágine de observación y fiscalización permanente acerca de su persona, vida y obra, que no había previsto. Ante ello, respondió negando la filiación autobiográfica de la novela, la naturaleza de sujeto censor y crítico de su personaje protagonista y hasta su misma condición de escritora. La impostura que hubo de adoptar ante los periodistas le ocasionó sonados enfrentamientos con algunos de ellos, sobre todo porque ni la forma de pensar ni de conducirse de "la escritora Carmen» encajaba en sus «literarios y masculinos estereotipos».

\subsection{La fuga mistica ante un "matrimonio luz de gas" y la falta de libertad}

El 6 de mayo de 1946, Laforet contrajo matrimonio con Manuel Cerezales, con quien, entre 1946 y 1957, tuvo cinco hijos. Cerezales había nacido en 1909 en Villaciervos, una pequeña localidad minera de Orense. A los 15 
años, había quedado huérfano de madre y a los 23, también de padre. Había cursado la enseñanza secundaria interno en un colegio religioso y después la carrera de Derecho, si bien nunca había llegado a ejercer como abogado, dado que su vocación había sido siempre la literatura y el periodismo. Se había trasladado a Madrid al finalizar la guerra, en la que había combatido en el bando nacional por su condición de carlista convencido y su ferviente catolicismo, pese al cual manifestó siempre en sus artículos una actitud religiosa abierta y tolerante. Su orfandad lo había forzado a valerse por sí mismo, así como lo había sumido en un estado de aislamiento que se acentuaría, debido a sus problemas de audición, con el paso del tiempo. De carácter melancólico y taciturno, Carmen pronto interpretó como reproches hacia ella su temperamento lánguido y decaído. Desde bien temprano, surgieron desavenencias entre la pareja, tanto relativas a las cuestiones domésticas como a las literarias, discrepancias acuciadas en ocasiones por los apuros económicos que la familia, de una burguesía modesta, atravesaba. Una de las crisis matrimoniales más graves, por la que Cerezales amenazó a Carmen con separarse, se produjo en el verano de 1958, con motivo de la estancia de ambos en Tánger, donde, desde julio de 1957, el primero se había trasladado en su condición de director del periódico España. Allí, de la mano de su amigo Emilio Sanz de Soto, y contrariando los deseos de su esposo, Carmen había entrado en contacto con el mundo cosmopolita y bohemio de la ciudad norteafricana, convertida por entonces en el refugio de toda una generación de escritores e intelectuales -Leonard Berstein, Virgil Thompson, Aaron Copland, Tenesse Williams, Truman Capote, etc.- - algunos de los cuales exhibían su homosexualidad sin reparos.

A Cerezales, que destacaba el vitalismo, la autenticidad y la generosidad de Carmen, le contrariaba en cambio su carácter distraído, desordenado y olvidadizo, de forma que le acusaba de ser incapaz de «llevar metódicamente sus cuentas y de negarse, con tozudez digna de mejor causa, a reglamentar cualquier aspecto de su vida» (Caballé y Rolón, 2010: 343-344). Por su parte, durante los primeros meses de convivencia de la pareja, la escritora ya había descubierto que Manuel Cerezales no iba a brindarle, contra lo que había supuesto, la seguridad que ansiaba, de forma que combatía su «yugo psicológico-depresivo" con la rabia (Cerezales, 2009: 151). Considerándose menos culta que su marido, de cuyo consejo literario se había dejado guiar al principio, pronto la escritora no supo cómo sustraerse a su influencia y a la persecución de unos sueños que no eran los de ella. A este respecto, Carmen confiesa que llegó a temer incluso que sus éxitos literarios despertaran los celos de su pareja, quien, tras la separación, publicó unas excelentes novelas para niños. Mientras que la autora escribía a partir de lo vivido, Cerezales, que afirmaba que su mujer no era una novelista "creadora», en el sentido de que no «inventaba», la instaba, en cambio, insistentemente a que dejara atrás el autobiografismo (Caballé y Rolón, 2010: 499). Es muy probable que la razón última de esta obstinación de Cerezales fuera el temor a verse convertido él mismo en protagonista de uno de sus libros. De hecho, en 1971, con motivo 
de la separación del matrimonio, para que Carmen pudiera manejarse como soltera - puesto que sin el consentimiento del que fuera su marido no podía en aquellos tiempos alquilar una casa a su nombre, ni comprarla, ni disponer de una cuenta corriente, etc.- éste le impuso la condición de que firmara un documento privado ante notario en el que se comprometía a no escribir nada que tuviera que ver con su largo matrimonio «luz de gas» (Caballé y Rolón, 2010: 499). Asimismo, en la única visita que su padre le hiciera en los años cincuenta, Carmen aceptó la petición de éste de "que no escribiera nada referente a su vida», y esto aun cuando la escritora se dijera a sí misma: «[...] pero su vida era también la mía. Y no es que yo quisiera contarla, pero esa petición era una mutilación, una cortapisa a mi capacidad creadora que nunca debí aceptar» (Cerezales, 2009: 252).

Para huir de aquella problemática, tanto doméstica como artística, en 1951, Carmen se creó para sí misma una "experiencia mística» que momentáneamente le permitió refugiarse

[...] en esa cómoda idea del oficio de ser mujer que una vieja esclavitud ha puesto en muchas mentes, tanto de hombres respecto a la mujer como de mujeres respecto a sí mismas. [...] Comprendo que es una forma de atarme yo sola, como los personajes de Buñuel en El ángel exterminador, que no pueden salir del cuarto porque no se deciden a dar un paso. (Cerezales, 2009: 106-108, 55)

Así, entre 1951 y 1957, aquella supuesta «revelación» le llevó a hacer «las mayores idioteces y a meterse por todos los vericuetos de nuestro catolicismo español en lo que tiene de veneno religioso y en lo que tiene de absurdo y enmohecido y todo" (Cerezales, 2009: 110-111). Dicha "deriva» vino precipitada por la relación amorosa que, durante aquellos mismos años, mantuvo con la tenista Lilí Álvarez, mujer cosmopolita, culta, seductora y ansiosa de que la mujer adquiriera un papel más relevante en la defensa de la religión católica. Carmen encontró en ella la protección y el amparo que por entonces necesitaba. De dicha relación ha quedado como testimonio un revelador epistolario que aún no ha sido íntegramente publicado. La ruptura entre ambas se produjo en 1957, a causa del último embarazo de la escritora, que la deportista le reprochó hasta el punto de negarle en lo sucesivo la palabra. A su vez, Carmen respondió a su «estampida» con una última y esclarecedora carta:

Yo, en cambio, te espero con los brazos tendidos... Tengo que esperarte. O bien tirarme al surco y marcharme contigo todo recto, caminito del infierno, cosa que tú eres la primera en prohibir... como es natural. [...] No, niña mía. Aunque tú te obstines en creerlo y en disfrazarlo, en tu sufrimiento no hay nada espiritual (como nada espiritual hay en el mío, cuando sufro también) y hay que saberlo, y hay que querer purificarse.

La separación de Laforet coincidió también con el matrimonio de su hija Cristina, sostén fundamental en su vida, así como con la no menos impor- 
tante marcha de la casa de Julia Muñoz, una criada avulense que, en 1953, había empezado a trabajar en ella, tomando enseguida sus riendas. "Julia liberó a Laforet de la colaboración que sí le solicitaban las sirvientas que había tenido hasta entonces [...]; significaría para ella la libertad doméstica, la garantía de que su necesidad permanente de vivir a su manera no debía repercutir en su familia» (Caballé y Rolón, 2010: 251). Sin embargo, en el momento de la separación, la escritora se vio también falta del apoyo de algunos de sus hijos. Sin duda, esto pudo deberse, por un lado, al hecho de que a éstos les «resultaba difícil complacer a su madre en sus dos modalidades: la distante y la cercana» (Cerezales, 2009: 20-21) y, por otro, a la negativa de Carmen a que sus hijos siguieran sus propias inclinaciones artísticas, puesto que proyectaba en ellos los padecimientos que éstas le ocasionaban. Así, por ejemplo, al hablar de la relación con su hijo Manuel, la propia escritora comentaba:

Créeme, si yo hubiera podido desviar tu destino, habría cometido el error de hacerlo. Pero tú elegiste ser artista y te querías bohemio y libre a pesar de mi dolor y de mi resistencia. La vida de un artista es terrible, te lo anuncié. [...] Yo no quería que mi hijo luchara contra todos los demonios. Yo quería algo más sencillo, más fácil. (Cerezales, 2009: 222-224)

\subsection{La imposible ficción y la enfermedad degenerativa}

Tras separarse, Carmen se alojó provisionalmente en varias ciudades, haciéndolo siempre en casas de fieles amigas —-Linka, Concha Ferrer, etc.—, o de su hija Cristina. En marzo de 1971, alquiló un inmueble en Madrid, en la calle Lagasca, donde lo mismo proyectó montar un negocio de libros para bibliófilos que un viaje recorriendo todo el continente americano. Se mantenía gracias a las conferencias que pensaba impartir en distintas universidades. Con este propósito, le escribió a su amigo Ramón J. Sénder, quien logró que el nuevo chairman de la Universidad del Sur de California, Theodore Sackett, se ofreciera a la escritora como coordinador de una gira nacional por Estados Unidos, que finalmente se acordó para la primavera de 1972. Mientras llegaba esa fecha, Carmen Laforet no renovó el contrato de alquiler del piso de Lagasca y se instaló temporalmente en Torrelaguna, en la finca de sus amigos Jesús Alfonso Parra Garrigues y Dolores Viudes. Puede decirse que fue a partir de aquí cuando empezó de verdad su errancia. En casa de sus amigos, se propuso formar una colonia de artistas en algún lugar de Grecia, y le escribió a Sackett renunciando a la gira americana, porque no se veía con fuerzas para afrontar el desafío. Por su parte, a Sénder le decía en una carta que dar conferencias le horrorizaba y que tal vez pudiera «hacer el viaje más adelante en una compañía de circo cuidando elefantes o yendo a Estados Unidos a cuidar ancianos» (Caballé y Rolón, 2010). En el verano de 1972, la escritora dejó la casa del matrimonio Parra y se instaló de nuevo en Madrid, en la de su amiga Rosa Cajal, donde pensó en París como un posible destino, aunque Sénder, enamorado de ella, le seguía invitando a que lo visitara en 
San Diego, propuesta que la escritora esquivaba. Entre tanto, planeó también la posibilidad de ir a Roma, aprovechando que el matrimonio Parra tenía previsto un viaje a la capital italiana. En Roma, permaneció entre 1972 y 1977, y contó con la ayuda maternal y protectora de otras tantas mujeres, María Teresa León entre ellas. A la accidentada y dura estancia en Roma, jalonada de no pocos viajes a España y dentro de Italia, le siguieron, entre 1982 y 1998, cinco viajes a Estados Unidos. En ellos, una de sus obsesiones era no quedarse sola. Debió de ser por esa época cuando la escritora comenzó a padecer los síntomas de la larga enfermedad degenerativa que, una vez avanzada, le forzó primero a ser atendida temporalmente por varios de sus hijos en sus casas y, finalmente, ingresada en una residencia de La Moraleja. Murió en Madrid el 28 de febrero de 2004. Como puede verse, el itinerario seguido por Laforet en esta etapa no es:

[...] el de alguien que se mueve en una dirección determinada. [...] Los lugares recorridos por Laforet $[\ldots]$ no le interesan más que como posibles lugares donde poder descansar de sus dramáticos esfuerzos por demostrar a los demás y a sí misma que puede valerse por sus medios. Lo único que importa [...] es que su talento creador se ha ido secando progresivamente, irremediablemente, y no sabe cómo combatir esta sensación de fracaso, más que huyendo. (Caballé y Rolón, 2010: 384-385)

Así, aunque tras sus cuatro primeras novelas, todas ellas autobiográficas — Nada (1945), La isla y los demonios (1952), La mujer nueva (1955) y La insolación (1963)—, Carmen se había propuesto, ya a comienzos de los años sesenta, componer una trilogía ficticia — Tres pasos fuera del tiempo-, lo cierto es que, tras su separación, pese a haberse alejado de la «alargada sombra» de su marido, carcomida por la inseguridad y enferma, no publicó en vida ningún otro libro. Sus mismas ideas acerca del feminismo, en el que veía un error que había conducido «a la mujer a liberarse de la presión masculina en las mismas profesiones y bajo las mismas convenciones sociales en las que se habían movido los hombres» (Caballé y Rolón, 2010: 212213), están transidas de los avatares literarios, domésticos y amorosos de su propia vida:

[...] toda mujer por el hecho de serlo tendría desde que nace una renta asegurada para vivir, renta que entregaría el Estado sacándosela a todos los hombres. Cuando tuviera niños, mientras fueran pequeños las rentas se le multiplicarían muchísimo. A la mujer le estarían prohibidos toda clase de trabajos pesados. Los hombres guisarían, lavarían, serían ingenieros, negociantes, artistas, obreros de fábrica [...] A las mujeres se les exigiría que se cuidasen, y las que fueran más bonitas tendrían más dinero, también las más inteligentes porque la crítica de lo que hicieran los hombres estaría encomendada a la mujer. La mujer no podría pertenecer nunca a un partido político ni inventarlo, pero sería la única que tendría voto. No sería artista, pero sí crítico de arte, etc, etc. Nada de pisarles el terreno a los hombres, sólo alentarlos o hundirlos de la manera más femenina. (Caballé y Rolón, 2010) 


\section{El mundo propio y el feminismo «a su manera» de Carmen Martín Gaite}

[...] como tampoco me atrevería a fugarme a la luz del sol, lo sabía, me escaparía por los vericuetos sombríos de la imaginación, por la espiral de los sueños, por dentro, sin armar escándalo ni derribar paredes, lo sabía, cada cual ha nacido para una cosa.

(Carmen MARTín GAITE. El cuarto de atrás)

\subsection{La niña solitaria que soñaba con ser actriz mirando por la ventana}

Carmen Martín Gaite nació en Salamanca el 8 de diciembre de 1925. Por decisión de su padre, José Martín, de profesión notario y afín a las ideas de la Institución Libre de Enseñanza, la niña estudió sus cursos de primaria en el piso familiar de la plaza de los Bandos con ayuda de preceptores particulares. Su infancia estuvo sujeta a una fuerte disciplina y a una severa moral de trabajo, cuyo único contrapunto eran los juegos con su hermana Ana María en el trastero de la casa o "el cuarto de atrás» - título que la escritora daría en 1979 a su autobiografía-, donde «reinaban el desorden y la libertad [...] y nada estaba prohibido» (Martín Gaite, 1981: 187). Por entonces, Carmen sólo dejaba la casa, siempre «escoltada», para asistir los domingos a misa y confesar, acompañar a su madre, María Gaite, a las tiendas de telas y decoración, a las que, como ama de casa, era gran aficionada, y visitar, en Semana Santa y Navidad, la casa madrileña de su abuela paterna, donde el orden, la limpieza y la religiosidad eran «tres nociones distintas y un solo Dios verdadero al que había que rendir culto por todos los rincones de aquel convento", cuyo bostezo se le propagaba hasta el punto de sentirse "tragada por una ballena» (Martín Gaite, 1981: 75-78). Por estos motivos, apenas gozó de amigos y amigas durante su infancia, por lo que comenzó a aislarse, a crearse sus propios interlocutores secretos y a fantasear mirando por la ventana, umbral más allá del cual el mundo se volvía misterioso, un ámbito donde cabía lo inexplorado y que a ella le era negado. Su inconformidad con tales hábitos hizo que, desde bien pequeña, entreviera en el teatro y en su deseo de ser actriz la oportunidad de «ser otra» y de «llevar una vida distinta». No obstante, las únicas salidas que la autora recuerda particularmente asociadas a la sensación de espontaneidad y libertad son las de los veraneos en San Lorenzo de Piñor (Orense), la aldea materna. Allí jugaba con sus primos y los niños de la zona en contacto con la naturaleza, acudiendo a romerías y verbenas, aprendiendo gallego, etc.

A la coartada e insatisfecha curiosidad de su infancia vino a sumársele, durante su adolescencia, transcurrida en plena guerra, la imposición del silencio y del miedo suscitado por ella, alarma y cautela aún más intensa si tenemos en cuenta la condición de Salamanca de cuartel general de Franco durante la contienda y la frecuencia de los bombardeos en ésta. 


\subsection{La adolescente novelera que se veía a si misma como una antiheroina}

La adolescencia de Carmen estuvo presidida por dos sensaciones: el frío y el miedo (Martín Gaite, 1981: 57). Aunque José Martín quiso que cursara su enseñanza secundaria en el Instituto Escuela madrileño, el estallido de la guerra le obligó a inscribirla en el Instituto Femenino de Salamanca, un centro público, "donde había mucha mezcla» (Martín Gaite, 1981). Entre algunos de los profesores que le impartieron clase, se cuentan Salvador Fernández Ramírez y Rafael Lapesa. En este centro, Carmiña conoció a la primera amiga íntima de su vida: una niña, hija de maestros republicanos encarcelados, a la que, por su orgullo y valentía, presenta como antítesis de sí misma. Influenciada por su madre, gran lectora de folletines sentimentales, así como por sus lecturas de las exitosas novelas amorosas de la época, de autoras como Carmen de Icaza y Elizabeth Mulder, Carmen y su amiga comenzaron a escribir en común una novela rosa que transcurría en Bergai, una exótica isla. En dicha novela, la joven vertía, por un lado, su deseo de conocer, sola, la aventura de vivir al raso; por otro, su necesidad de verse a sí misma con los aparentes visos de modernidad que ponían de manifiesto sus literarias heroínas - mujeres que vivían solas, independientes, trabajadoras, fumadoras, de hábitos ligados a la sociedad de consumo que por entonces comenzaba ya a palpitar y de un comportamiento sexual que en absoluto contravenía la moral de la época, que obligaba a la mujer a contenerse y saber esperar-; y por último, su pretensión de relacionarse con los varones con cierta seguridad, permitiéndose así en la literatura licencias e iniciativas amorosas que jamás se concedía en su vida real:

Me gustaría no hablar más, atreverme a apoyar la cabeza en su hombro. Me concentro en esta idea que me exalta, pero de inmediato se ve acosada por un ejército de razones. [...] Al final, mi cabeza permanece inmóvil, como era de esperar: caer en la tentación siempre ha sido más difícil que vencerla (Martín Gaite, 1981: 39).

Educada en la salvaguarda de la normalidad y en la oposición al riesgo, Carmen se presenta a sí misma como una de aquellas «chicas decentes y sensatas de la nueva España» (Martín Gaite, 1981: 154), a quien las grandes pasiones amorosas - aquellas que cantaban las coplas de la época, a las que por ello era tan aficionada - le estaban vedadas. A aquella educación presidida por el recato y el encorsetamiento hay que sumar la percepción que de sí tenía la escritora como un ser inseguro y torpe, sobre todo cuando se trataba de relacionarse con los varones:

De ahí me han venido siempre los fallos en el amor, del miedo a que alguien pudiera dejarme sin palabras, reducida al mero poder de mi mirada o de mi cuerpo. «Tú eres poco lanzada —me decían mis amigas, cuando empecé a ir a bailar al Casino-, no das pie». A los hombres había que darles pie, las chicas lanzadas sabían jugar con sus ojos, con su risa y con el movimiento de su cuer- 
po, aunque no tuvieran nada que decir. Y los hombres que me gustaban, y a los que tal vez yo también gustaba, se iban haciendo novios de otra. Aprendí a convertir aquella derrota en literatura, [...] y así pasaba el tiempo [...]. (Martín Gaite, 1981: 182-183)

En las risibles torpezas en que incurrían los protagonistas de las películas del cine mudo - otra de las referencias que marcaron su adolescente educación sentimental-, la aislada, solitaria, ventanera y novelera Carmiña reconocía su «mediocridad patosa de anti-heroína» (Martín Gaite, 1981). El rechazo de sí misma le llevaba, en cambio, a proyectar su deseo de ser distinta en las audaces y desenvueltas mujeres de los films protagonizados por actrices como Ingrid Bergman, Shirley Temple, Paulette Godard, Ana Mariscal y, sobre todo, Diana Durbin - actriz y cantante canadiense que alcanzó gran popularidad en los años treinta y cuarenta protagonizando cándidas películas de corte romántico-. Sólo cuando supo ponerse los chifles para rizarse el pelo sin ayuda de su madre, Carmen Martín Gaite se consideró mayor de edad: "Fue como desprenderse del claustro materno», dirá (Martín Gaite, 1981: 66).

\subsection{La estudiante universitaria que temía que se dijera de ella que era una fresca}

El 19 de octubre de 1943, Carmen comenzó sus estudios de Filosofía y Letras en la Universidad de Salamanca, donde por fin disfrutó de sus primeras amistades masculinas, al poder alternar con chicos en las aulas. Ella era la única joven entre sus doce compañeros - Agustín García Calvo e Ignacio Aldecoa entre ellos-, procedentes casi todos de provincias del norte. Pronto se vio fascinada por la personalidad del vitoriano, un joven desinhibido y ácrata, que gustaba del contacto con los desheredados de carne y hueso y que renegaba de los «símbolos» que ella aún parecía tomar demasiado en serio: la distinción de la clase media, los estudios superiores y la cultura libresca. Con éste y sus amigos hizo pronto sus primeros novillos. Con el vitoriano compartía, asimismo, su bohemio deseo de enrolarse en una compañía de teatro o de circo. De hecho, durante su primer curso de carrera, representaría los Entremeses cervantinos con un grupo universitario. Sin embargo, siendo éste su principal anhelo, «a finales de los cuarenta, al menos para una chica, dedicarse al teatro llevaba aparejada cierta connotación peyorativa. "Quien mal anda, mal acaba: es una cómica — decían las señoras arrugando la nariz-》 (Martín Gaite, 2006: 215). Miedosa y horrorizada por que alguien pudiera decir de ella que era una "fresca», Carmen renunció a aquel sueño por temor al qué dirán, aun cuando éste se le antojara "ponerse el mundo por montera» (Martín Gaite, 2006: 215).

En el verano de 1944, viajó con su padre al balnerario de Cabreiroá, en Verín, donde, más que vivir, se creó para sí una experiencia amorosa con el displicente hijo del gerente, experiencia que interpretó en su obra El balneario (1954), otra vez en clave de novela rosa. Durante el estío de 1945, obtuvo una 
beca de estudios para viajar a Coimbra (Portugal), a fin de documentarse sobre el cancionero galaico-portugués. Para ello, hubo primero de convencer a su padre y después cumplir con el Servicio Social, condición sine qua non para que una joven pudiera viajar al extranjero en aquellos tiempos. Sin embargo, no debió de dar las suficientes muestras de tener madera de futura madre y esposa, pues los informes no fueron muy satisfactorios y tuvo que cumplir a su regreso algunos meses más de prestación como sanción. Durante este viaje, mantuvo una nueva relación amorosa con un estudiante de Oporto, marcada también por un "casto y caballeresco» ritual de seducción. Durante esta estancia, visitó asimismo Oporto y Lisboa, así como entró en contacto con la literatura portuguesa, de la que más tarde haría magistrales traducciones. Durante el verano de 1948, viajó a la Universidad de verano de Cannes, donde, según dijo, conoció «por primera vez, a sus veintidós años, el sabor auténtico de la libertad» (Martín Gaite, 1993).

\title{
2.4. La escritora de la generación del 50 y su neorrealista himno de taberna
}

\author{
«Nos basta una cabaña \\ para poder vivir \\ y un pedazo de tierra \\ para poder morir.»
}

(Vittorio DE SiCA y Cesare ZavatTini. Milagro en Milán)

En noviembre de 1948, Carmiña se trasladó sola a Madrid para cursar su doctorado en Románicas. Hasta que su familia se mudó en 1950 a la capital, se alojó en una pensión. Por entonces, trabajó haciendo fichas para el diccionario de la RAE y dando clases en un instituto de bachillerato a jovencitas. Aunque en aquella época ya había renunciado a sus sueños de ser actriz, pronto, por mediación también de Ignacio Aldecoa, entabló amistad con Alfonso Sastre y Mayra O’Wisiedo. Ésta le fascinó por «su desprecio por el qué dirán, su caminar con zapato plano a largas zancadas y aquellos gorritos tan atrevidos que se ponía» (Martín Gaite, 2006: 215), gorritos que serían más tarde un distintivo de la escritora misma. Gracias a ambos, conoció a gentes de la escena como Alicia Hermida, Berta Riaza, Agustín González, María Dolores Pradera, Adolfo Marsillach, etc. En aquel Madrid de finales de los cuarenta, también de la mano de Ignacio, se integró, asimismo, en un grupo de amigos, procedentes en su mayoría de provincias, y constituido, entre otros, por Jesús Fernández Santos, Medardo Fraile, Alfonso Sastre, Rafael Sánchez Ferlosio, Manolo Mampaso, etc. y el propio Ignacio. Mayra y Carmen fueron los únicos miembros femeninos del mismo hasta la incorporación a éste de Josefina Rodríguez en 1950. Por aquel entonces, Carmiña seguía aún sujeta a su severa disciplina de estudio, encaminada a doctorarse y a obtener una beca del Consejo de Investigaciones Científicas. Sin embargo, nuevamente, Ignacio y sus amigos le arrancaron de aquella y le pusieron en contacto con la vida madrileña, haciendo 
que abandonara «aquellos remordimientos de buena estudiante que piensa que pasear y beber vino y oír historias es estar perdiendo un poco el tiempo, rota aquella barrera de superioridad y pena con que al principio los miraba» (Martín Gaite, 1973: 37-38). Aquel grupo de «malos estudiantes, pero buenos escritores» tenía uno de sus núcleos neurálgicos en la pensión Garde, situada en el número 41 de la calle de San Marcos. En aquel centro de bohemia y disparate, se habían venido a juntar, entre otros, Rafael Santos Torroella, Ángel Crespo, Pedro Bueno, Juan Arboleya, Carlos Edmundo de Ory e Ignacio Aldecoa. Junto a otros - Francisco Nieva, Chicharro hijo, Silvano Sernesi, etc.-—, estos dos últimos habían creado, en 1945, el manifiesto poético del postismo, uno de los primeros «vanguardismos» de la posguerra. Otro de sus lugares de encuentro fue la tintorería, sita en la calle de la Libertad, de doña Lola, madre de su amigo Francisco Pérez Navarro. Doña Lola, una mujer «encantadora, inteligente y maternal», tan pronto les daba de merendar y les prestaba algún dinero, como recogía sus recados y escuchaba sus confidencias (Martín Gaite, 2006: 41, 43). Junto a alguno de aquellos compañeros, Carmen asistía también puntualmente a una tertulia literario-filosófica en un conocido restaurante de la calle Zorrilla. Pero, sin lugar a dudas, los lugares vitales de aquella generación llegada de provincias, sin casa propia en la capital, fueron, por excelencia, las calles y las tabernas, sobre todo las cercanas a la pensión de Ignacio, y las de los aledaños de San Marcos, entre las calles Colmenares, Válgame Dios, Barbieri, Libertad, Augusto Figueroa y la plaza de Chueca. Aunque no eran tan asiduos a ellos, también visitaban los cafés de la época: el Comercial, el Gijón, el Lyon, el Varela, etc, "que parecían concebidos como un refugio intemporal para hacer más llevadera la espera del porvenir» (Martín Gaite, 2006: 48-49). Aquella espera del porvenir pasaba, además, por visitar oficinas inconcretas, la mayoría de ellas redacciones de periódicos y revistas, donde nadie les hacía demasiado caso. Algunos de aquellos jóvenes, incluso ella misma, colaboraban ya por entonces esporádicamente en medios escritos como La Hora, Juventud, Alcalá, Clavileño, Indice, Correo Literario y El Español. Además de una carrera en vías de profesionalización, en los años cuarenta y cincuenta, «escribir era [...] un atributo muy desnudo de prestigio» (Martín Gaite, 2006: 55). La propia Carmen recuerda cómo ella misma tardó muchos años en atreverse a poner «escritora» en su pasaporte; fui «licenciada en Filosofía y Letras — dirá—, hasta bien entrados los sesenta, porque lo de "sus labores" tampoco lo admitía" (Martín Gaite, 2006: 55).

En 1953, contrajo matrimonio con Rafael Sánchez Ferlosio. La pareja se instaló en un pequeño apartamento de la calle Doctor Esquerdo, por entonces un bulevar sin semáforos de la periferia. Antes de vivir en él, el joven matrimonio residió unos meses en Roma, en casa de los abuelos maternos de Rafael, periodo durante el cual Carmiña se familiarizó con el neorrealismo italiano.

El aldabonazo espiritual para toda aquella generación que vivía sus sueños profesionales en precario llegaría aquel mismo año. Éste fue producto del mecenazgo de Antonio Rodríguez Moñino. Durante la Guerra Civil, Rodríguez Moñino había pertenecido al grupo que había colaborado en Hora de Espa- 
$\tilde{n} a$, aquella revista valenciana «donde se agruparon los últimos disidentes del franquismo, antes de morir o verse obligados a emigrar» (Martín Gaite, 2006: 55). En el verano de 1953, Moñino encargó la dirección de Revista Española, la única de la época no sujeta a subvención oficial, a Rafael Sánchez Ferlosio, Ignacio Aldecoa y Alfonso Sastre. Dificultades de la censura aparte, dicha revista tuvo una vida efímera - seis números-, lo que da una idea del panorama literario y de las dificultades que atravesaban los escritores en aquel momento. En sus páginas, confluyeron el existencialismo francés, el neorrealismo italiano y la novela norteamericana. Asimismo, dio acogida a muchos de los escritores españoles mencionados más arriba, Carmen Martín Gaite incluida. En el existencialismo, la escritora y toda su generación veían la antípoda de la falsa moral triunfalista que escamoteaba la realidad de la opresión política y la injusticia (Martín Gaite, 2006: 68). En cambio, la identificación de Gaite y sus amigos con las antiheroicas historias neorrealistas, protagonizadas por desarrapados del extrarradio, adolescentes sin oficio, jubilados, humildes oficinistas, etc., tenía que ver con su, por entonces, modesta precariedad, su condición de emigrantes de provincias que habían llegado a la gran ciudad, como aquellos, "con la noche y el día", en busca de un porvenir que se les resistía. Desde las ventanas de su apartamento de Doctor Esquerdo, en el que residió casi hasta el final de su vida, la propia Carmiña fue testigo, en los años cincuenta, del crecimiento del núcleo de chabolas edificado en la hondonada de La Elipa, uno de los barrios suburbiales que, como los del Puente de Vallecas, Entrevías, El Pozo del Tío Raimundo, Palomeras o El Cerro del Huevo, se expandieron sobremanera en aquella época. Dolores Martínez Quesada, la asistenta del matrimonio Sánchez Ferlosio-Martín Gaite durante veinte años, había llegado a La Elipa el otoño de 1953 desde Bejíjar (Jaén), junto con su esposo — que había estado en la cárcel一, tres hijos y uno en camino, que había perdido al haberse visto forzada a dormir en la calle. Además, de soltera, Carmen había prestado ayuda en un dispensario de Vallecas, donde había entrado en contacto con la descarnada realidad de los suburbios, experiencia que reflejó más tarde en algunos de sus cuentos, entre ellos, La conciencia tranquila, en el cual dirá: «la mía, de señorita burguesa de provincias había quedado sacudida para siempre» (Martín Gaite, 2006: 128). Pero, sin duda alguna, la escritora salmantina vio también en el neorrealismo italiano ciertas concomitancias con la doctrina evangélica y el humanismo cristiano, el mismo que por entonces comenzaba a predicar el clero contestatario en los arrabales. Ella misma andaba, en aquella época, intentando desasirse de los últimos resabios de su «catolicismo oficial» anterior y abrazar, como opción de protesta frente a aquella religión acartonada y estéril en la que había sido educada, un incipiente laicismo, la estética neorrealista de la redención sin agresividad, que identificaba pobreza y salvación, y la fe mesiánica en la pedagogía y la solidaridad con los humildes heredada de las corrientes liberales fomentadas por la Institución Libre de Enseñanza y el pensamiento krausista. Su religiosidad católica evolucionó, así, desde la ortodoxia hacia un humanismo cristiano teñido de piedad para con los más desfavorecidos, y en él confluía, además, la fascinación por todos los seres marginales y perseguidos. 


\subsection{Una mujer abierta y secreta a la vez}

El último número de Revista Española (1954) coincidió, para Carmiña, con su consagración literaria gracias a la obtención del Premio Café Gijón de Relato Corto por su novela El balneario, galardón impulsado e instituido en 1949, entre otros, por Fernando Fernán Gómez, Gerardo Diego, Enrique Jardiel Poncela y Camilo José Cela. En 1955, nació su primer hijo, Miguel, fallecido a causa de una meningitis a los pocos meses. Su hija Marta vendría al mundo al año siguiente. En 1957, obtuvo el Premio Nadal con su novela Entre visillos, ejemplo del realismo generacional. En 1970, se separaría de Rafael Sánchez Ferlosio, circunstancia que, coincidente en el tiempo con el boom de la literatura hispanoamericana en España y su relegación momentánea de nuestro panorama literario, le trajo consigo una grave crisis anímica, pronto agravada por la pérdida de sus padres (1978). Para hacerle frente, se consagró a recopilaciones de sus cuentos y poesías, ensayos historiográficos y de crítica. Asimismo, impartió clases de teoría literaria en el Barnad College de Nueva York (1978), además de conferencias en diversas universidades americanas: Nueva York, Columbia, Rutgers, Yale, Wellesley, Boston, Oberlin, Chicago, Texas, Virginia, Vassar...

Aunque son muy pocos los detalles que Carmen nos brinda, en su autobiografía y en sus escritos, acerca de su relación de pareja, en páginas dispersas nos ofrece, sin embargo, algún atisbo. Así, en 1972, ya separada, cuando presentó finalmente su tesis doctoral de Filología Románica, le dedicó esta obra a Ferlosio. En dicha dedicatoria, puede leerse: «Para Rafael, que me enseñó a habitar la soledad y a no ser una señora». En algunos de sus textos literarios, caso del cuento Un día de libertad, la autora parece evocar sus huidas del hogar matrimonial y sus paseos, sola o en compañía de su hija, por la sierra madrileña. En este sentido, desde 1960, Carmen había ido frecuentando y pasando largas temporadas sola en El Boalo, una población de aquélla, donde descansan sus restos en la actualidad. En 1985, murió su hija. Poco dice también la escritora acerca de la relación con ella. Aun cuando en ciertas páginas afirma que eran muy amigas, en otras diseminadas en su ingente obra deja entrever que ésta, pese a especial, no dejó de estar en cierto modo presidida por un desfase generacional que dificultaba el entendimiento entre ellas. Así, por ejemplo, en la dedicatoria de su ensayo Usos amorosos de la postguerra, leemos: «Para todas las mujeres españolas, entre cincuenta y sesenta años, que no entienden a sus hijos. Y para sus hijos, que no las entienden a ellas» (Martín Gaite, 1987b).

Aunque el éxito que le granjeó Entre visillos hizo que, durante mucho tiempo, se la encasillara en el género realista, lo cierto es que la mayor parte de su obra gira en torno a preocupaciones autobiográficas - la rutina, la comunicación y la incomunicación, la soledad, la relación entre padres e hijos, el poder de la fantasía, etc.- - en tanto que el resto de sus trabajos está más vinculado a la literatura infantil y a los cuentos de hadas. Así, como ella misma dijera de su amigo Ignacio Aldecoa, podría afirmarse que Carmiña «vivió sin 
afianzarse del todo sobre la realidad, aunque no por eso negándose a explorarla y a entender, como pocos, lo insoportable que era. La conoció pactando con ella a ratos, y a ratos huyéndola para pedir albergue en la morada de la fantasía [...], donde le esperaba siempre una historia que le redimía del tedio de vivir» (Martín Gaite, 2006: 162). La escritora decía de sí misma que era muy suya, y que su intimidad tenía una "parte íntima inabordable». Fue por ello una mujer «abierta y secreta a la vez; tenía dos caras, una sonriente y otra trágica» (Martín Gaite, 2006: 24).

Al igual que su coetánea Carmen Laforet, Carmen Martín Gaite dijo tener "un feminismo a su manera», desde el que argumentaba que "cuando una mujer está ya picada por el feminismo, [...] suele tratar, sobre todo, de parecerse, aunque ella no lo cree, [...] suele imitar esos defectos del varón, que existen, y que tanto está denostando. [...] Es pasarse al bando de ese enemigo, que además no tiene por qué ser enemigo. Yo al hombre le tengo una enorme simpatía, cosa que las feministas me parece que no» (Soler Serrano, 1980).

\section{Conclusión}

Siguiendo el método de la sociología histórica y tomando como hipótesis de trabajo los presupuestos planteados por los estudios de género centrados en la crítica de la razón patriarcal — más concretamente, los que sostienen que la emancipación de las mujeres pasa por dotarlas y que se doten de mecanismos de autoafirmación desde los que poder superar la conciencia inferiorizada de sí que arrastran como resultado de la asunción como propia de la diferencia instituida por el discurso de la dominación masculina-, nuestra investigación ha abordado el proceso por el que Carmen Laforet y Carmen Martín Gaite fueron adquiriendo paulatinamente recursos para contrarrestar los perniciosos efectos de su socialización de género. Como hemos visto, dicha socialización se fundamentó en un dispositivo de feminización implantado en un contexto histórico en el que las distintas instancias de poder —educación, Iglesia, política, etc.- le dieron una nueva vuelta de tuerca al programa de racionalización de la vida de las mujeres que, desde tiempo atrás, había implantado una diferencia entre éstas y los varones, en función de la cual su destino era encarnar al «ángel del hogar». Así pues, como hemos tenido ocasión de comprobar, desde su más tierna infancia, las dos narradoras asumieron como propios el menosprecio y la inferioridad que les atribuyó el otro. En el caso de Laforet, esta circunstancia dio comienzo con la opresión ejercida sobre ella por la figura paterna, mientras que, en el caso de Martín Gaite, se debió a la coartada curiosidad y a la fuerte disciplina impuesta por su familia en aras de que su previsible destino doméstico no se frustrara. La falta de libertad de la que ya de niñas se resentían alentó sus deseos de ser actriz o de enrolarse en un circo, pensando acaso que tales oficios les permitirían llevar una vida distinta a la suya, que aborrecían. La asunción como propia de la infravaloración producto de su estatuto de dominadas tampoco halló coto en la adolescencia de ambas. Así, la marginación de la que Laforet fue víctima durante esta etapa se mani- 
fiesta con rotundidad en las agresiones físicas y psicológicas de su madrastra, así como en la pasividad y complicidad para con ellas de los varones de la casa. En el caso de Martín Gaite, su conciencia inferiorizada guardó, en cambio, relación con otros modelos de mujeres — amiga, protagonistas literarias y fílmicas - con las que se comparaba y que, por entonces, representaban para ella valores de los que creía que carecía: desparpajo, desenvoltura, audacia, libertad, seguridad en sí misma, etc. A esta autopercepción peyorativa había que sumar la asunción por la escritora de la imagen negativa que la sociedad proyectaba sobre las actrices y mujeres «lanzadas", interiorización que le llevó a optar por una dedicación socialmente más aceptada, así como a ser una "chica decente y sensata de la nueva España». No obstante, la etapa universitaria representó para ambas una excepción en lo que se refería a dotarse de verdaderos mecanismos de autoafirmación, puesto que las dos mujeres se forjaron un grupo de amigos y amigas en el seno del cual se sintieron iguales, valoradas y reconocidas, quizá por primera vez en sus vidas - conviene especificar que, en el caso de Laforet, esto sucedió sólo en el marco de la Tertulia del Palacio de la Virreina, puesto que, como hemos visto, algunos de sus compañeros universitarios no sólo la denigraban y la menospreciaban por su gusto y su pasión por la bohemia, sino por la proletarización y el desclasamiento que le había sobrevenido en la Ciudad Condal- En lo que respecta a las relaciones de pareja, parece que Laforet, dotada todavía de una conciencia desvalorizada durante buena parte de éstas, interiorizó la denigrante presunción de Cerezales de que sólo sabía escribir a partir de lo vivido y asumió las cortapisas a su capacidad creadora, tanto de su padre como de su marido. Asimismo, en su deriva religiosa y el conflicto entre ser lo que se le exigía — buena madre, amante esposa y abnegada ama de casay ser lo que quería —escritora—, llegó incluso a «atarse sola», aunque, eso sí, ya con plena y lúcida conciencia acerca de cómo y por qué lo hacía. Lúcida conciencia implícita también en la carta dirigida a Lilí Álvarez en su despedida definitiva. En el caso de Martín Gaite, por el testimonio presentado en la investigación, parece que su relación de pareja sí le permitió dotarse de mecanismos de autovaloración. Por otro lado, la crisis en que ambas artistas se sumieron tras separarse entrañó un indiscutible intento de reconciliación consigo mismas, un periodo de reflexión, de toma de conciencia acerca de su «diferencia» y, lo que es más importante, de búsqueda y conquista, más o menos fructíferas, de sus propias referencias internas. Así, si atendemos a la identificación laforetiana del feminismo de la igualdad como un error, nos damos cuenta de que, junto a su desaprobación, la escritora se dotó de un feminismo sui géneris que, siendo más bien de la diferencia, no era ni mucho menos el del «discurso autocomplaciente que cae en la tediosa moralina del "nosotras somos formidables", consuelo peligroso de tantos estancamientos, estafas e impotencias» (Amorós, 1991: 75). Por su parte, con su «feminismo a su manera», Martín Gaite rechazó de plano eso que Amelia Varcárcel, defensora de un feminismo de la igualdad de cuño ilustrado, ha reivindicado frente a los planteamientos del feminismo de la diferencia: el llamado «derecho al mal» (Varcárcel, 1980). Este «derecho al mal» presume que, «si en ética la 
universalidad es en sí misma un valor, y si resulta por otra parte que los hombres no parecen dispuestos a comportarse a la altura de nuestras "virtudes"”, deberíamos comportarnos todos "según el nivel de sus defectos y sus vicios» (Amorós, 1991: 157). Sin embargo, mientras que Varcárcel y Amorós han considerado revolucionaria esta igualdad de «igualar por abajo», Martín Gaite pensó que reproduciendo vicios y defectos no se contribuiría a crear una sociedad mejor, así como que su construcción pasaba por no imitar y mimetizar los elementos de la conducta propia del dominador, ya fuera éste mujer o varón. Parece, así, que nuestras antiheroínas rechazaron, del feminismo de la igualdad, lo que éste pudiera tener de un individualismo orientado hacia la afirmación exclusiva de la personalidad en el actual mundo del homo oeconomicus de las jerarquías, las promociones y los grados, y, del feminismo de la diferencia, aquel "iqué hermoso es ser mujer!» que nos proyecta de nuevo a la esfera de la intimidad, la inmediatez y la inmanencia. Desde este punto de vista, y en este contexto, diríase que tanto Laforet como Martín Gaite aspiraron a una «diferencia en la igualdad» o a una «igualdad en la diferencia» (Amorós, 1991: 73) que les hizo ser no feministas de un cuño u otro, sino feministas sui generis, a su manera. Por otro lado, el análisis sociológico-histórico de sus trayectorias vitales nos ha permitido conocer la dura lucha por la autonomía y la libertad de estas dos mujeres, así como sus esfuerzos por encontrar un espacio propio. $\mathrm{Al}$ mismo tiempo, su combate contra el dispositivo de feminización nos alerta contra la ideología conservadora y neoliberal que irrumpe con fuerza en la actualidad, que reivindica la naturalización del amamantamiento, el retorno a la familia tradicional, etc. Por último, la memoria y la experiencia de Carmen Laforet y de Carmen Martín Gaite ha de servirnos, a las mujeres de hoy en día, para que no perdamos de vista cómo el brillo y el éxito social están subsumidos muchas veces en la densa malla de la urdimbre patriarcal que las convirtió a ambas en élites discriminadas, es decir, en estrellas y víctimas por igual (García de León, 2011a). Nuestras «antiheroínas» fueron, pues, mujeres poderosas, aunque «desempoderadas» por la «estructura social de género que les tocó vivir y que tenían fuertemente interiorizada, a pesar de ellas mismas y sus conatos de salirse de la norma y de la norma de género» (García de León, 2011b: 1021).

\section{Referencias bibliográficas}

AldeCOA, Ignacio (1973). Cuentos completos. Madrid: Alianza.

Amorós, Celia (1991). Hacia una crítica de la razón patriarcal. Barcelona: Anthropos.

Caballé, Anna y Rolón, Israel (2010). Carmen Laforet: Una mujer en fuga. Barcelona: RBA.

Castilla del Pino, Carlos (1997). Pretérito imperfecto. Barcelona: Tusquets.

Cerezales Laforet, Agustín (1982). Carmen Laforet. Madrid: Ministerio de Cultura. Cerezales Laforet, Cristina (2009). Música blanca. Barcelona: Destino.

ELÍAS, Norbert (1994). «El cambiante equilibro de poder entre los sexos». En: Conocimiento y poder. Madrid: La Piqueta.

FuENTE, Inmaculada de la (2002). Mujeres de la postguerra: De Carmen Laforet a Rosa Chacel: historia de una generación. Barcelona: Planeta. 
GARCía de LEÓn, María Antonia (2011a). Cabeza modernalcorazón patriarcal. Barcelona: Anthropos.

— (2011b). «Clarice Lispector: una tragedia contemporánea de género». Revista Estudios Feministas, 19 (3), 1018-1022.

LAFORET, Carmen (1957). Novelas. Barcelona: Planeta.

- (2001). Nada. Barcelona: Crítica.

Martín Gaite, Carmen (1972). Usos amorosos del dieciocho en España. Barcelona: Lumen.

(1973). La búsqueda de interlocutor y otras búsquedas. Madrid. Nostromo.

(1981). El cuarto de atrás. Barcelona: Destino.

- (1987a). Desde la ventana. Madrid: Espasa Calpe.

- (1987b). Usos amorosos de la postguerra española. Barcelona: Anagrama.

- (1993). Agua pasada. Barcelona: Anagrama.

- (2006). Esperando el porvenir: Homenaje a Ignacio Aldecoa. Madrid: Siruela.

Soler SERrano, Joaquín (1980). «Entrevista a Carmen Martín Gaite». Programa $A$ fondo. Barcelona: Trasbals.

SORIANO, Juan Carlos (2007). «Ana María Martín Gaite: "Nadie, ni siquiera yo, conoció del todo a Carmiña"». Turia Revista Cultural, 83, 267-279.

SubIRATS, Marina (2013). Forjar un hombre, moldear una mujer. Gerona: Aresta.

VAlCÁrCEL, Amelia (1980). «El derecho al mal». El Viejo Topo, extra, n. ${ }^{\circ} 10$.

VARELA, Julia (1997). El nacimiento de la mujer burguesa. Madrid: La Piqueta.

VILlán, Javier (1974). «Entrevista con Carmen Martín Gaite». La Estafeta Literaria, 22.

WoOlf, Virginia (2001). Una habitación propia. Barcelona: Seix Barral.

\section{Bibliografía web}

La memoria inédita de Carmen Laforet

<http://www.elcultural.es/version_papel/LETRAS/9051/La_memoria_inedita_de_ Carmen_Laforet>

Las cartas de amor entre Carmen Laforet y Lilí Álvarez

<http://www.vanitatis.com/noticias/carmen-laforet-lili-alvarez-cartas-amor-2010111811820. html> 